\title{
Bioethics and Biolaw in the Vaccine against COVID 19 in Brazil
}

\author{
Silveira EA ${ }^{1 *}$ and Pires de Campos $\mathrm{CE}^{2}$ \\ ${ }^{1}$ Lawyer, Associate Law Firm, Estado São Paulo, Brazil \\ ${ }^{2}$ Biomedical Scientist, CEO of Cellular Mater Clinical Analysis Laboratory, Brazil
}

*Corresponding author: Eliana Aló Silveira, Lawyer, Master and Doctor, Associate Law Firm, Maritime Law Academy, Eua Vahia de Abreum 23, Bairoo Boqueirao-Cidade de Santos, Estado São Paulo, Brazil, Tel: +5513997644790; Email: ealo.advogados@ruben-eliana.com.br

\section{Editorial}

Volume 4 Issue 3

Received Date: August 31, 2021

Published Date: September 29, 2021

DOI: $10.23880 /$ abca-16000201

\section{Abstract}

The pandemic that was caused by COVID 19 made the world rethink ethical principles, morals, and justice, but always side by side with science. Never has bioethics been thought of so much, as a science that aims to provide the ethical content so that the human being is treated with dignity in the face of scientific techniques that concern life.

Bio law as a branch of legal science reveals itself as an indispensable branch to the legal system, to regulate and reconcile biotechnological advances with the principle of human dignity, founded on democracy and the defense of fundamental rights. In the international sphere, the right to life is foreseen in art. 4 of the 1969 American Convention on Human Rights, a document that was ratified by Brazil and comes from the regional system. In the Brazilian legal system, the provision is in article 1, clause III, of the Federal Constitution of 1988, which established human dignity as the foundation of the Democratic State of Law, also regulating, in article 5 , the right to life.

Starting from these guidelines that the human being should not be considered a "thing", or an instrument, the thought, even if philosophical, can lead to important conclusions in the field of scientific experimentation, especially with what has been happening in relation to the vaccines for COVID-19, that even if approved by a committee and following international protocols, one cannot guarantee with them the absolute protection of human dignity, principles of bioethics and fundamental human values. And, because of these discussions, the courts are urged to manifest themselves about the refusals of workers to be vaccinated.

Keywords: Bioethics; Biolaw; Human Rights; Justices

\section{Introduction}

A pandemic, according to the WHO (World Health Organization) [1], is the worldwide spread of a new disease. This occurs when an epidemic, a major outbreak affecting one region, spreads to different continents with sustained person-to-person transmission. In the case of COVID 19, a series of precautions were necessary to avoid contracting the disease, which could lead to death, due to the inexistence of treatment and vaccines to combat the disease.

In the world, as of November 10, 2020, there were $50,676,072$ confirmed cases and 1,261,075 deaths [2]. The
Regional Program on Bioethics, which is linked to the PanAmerican Health Organization (PAHO), has defined that bioethics works in the service of life, having a broad field of action that includes life, health, and the environment. Bioethics aims to bring science closer to new humanitarian issues, while biolaw provides legal protection through legal norms designed to protect human life and health, getting as close as possible to social demands [3]. Therefore, bioethics and law necessarily go hand in hand with human rights, and the intervention of law is necessary to regulate bioethical issues in a legitimate and sufficient manner. Biolaw is configured as a set of positive laws that aim to establish the obligatory observance of ethical commandments, based on 
appropriate legislation in the regulation of activities and relationships developed by bioscience and biotechnology. The purpose is to maintain human integrity and dignity in the face of scientific conquests in favor of life [4]. In the branch of legal sciences, biolaw aims to care for regulatory norms concerning the behavior of human beings in the face of advances in biological sciences and health sciences. In this context, bioethics plays its fundamental role in bringing together the human sciences and the biological sciences, and biolaw, through the principle of cooperation, makes a legal contribution to the progress and protection of life [5].

While ethics has universal intentions and is concerned with the internalization of good conduct and requires voluntariness (free adherence), law is concerned with the social effects of the externalization of certain conducts, imposes itself as obligatory and represents only the society in which it is inserted [6].

The right to health, an essential right for all, is foreseen in the Constitution of the Republic of Brazil, in its article 196: "Health is everyone's right and the duty of the State, guaranteed through social and economic policies that aim to reduce the risk of disease and other illnesses and to provide universal and equal access to actions and services for its promotion, protection, and recovery.

With the objective of protecting life, the authorities decided to impose restrictions and other measures to mitigate the dissemination of the disease, even if in opposition to the individual right of the human person. The autonomy, a bioethical principle, of people to come and go, was restricted. Would the right have the right to intervene in this way? With the reality of biotechnology and biomedicine, advanced research has given rise to legal conflicts not imagined by the legislator, requiring the birth of legal norms to solve such situations, with the main purpose of protecting life, without slowing down the progress of science. However, the progress of science in biotechnology is much faster and in general the legal rules are already outdated.

Thus, conflicts reach the judiciary and judges based on fundamental principles of law define the "rules of the game. This is what has been happening, when in the resumption of on-site activities employers and employees have sought in court the right to work $\mathrm{x}$ vaccine against COVID 19.

\section{The Right to Work}

The right to work, besides being a reflection of the freedom of the individual to choose his productive activity, is an important human right to dignify the human being.

Without work, you can't support yourself, you can't be totally free, and you can't choose the best way to lead your own life. Without work, it is not possible to pay for food, health, education, culture, leisure, etc. Without a source of income necessary for subsistence and development, the right to life itself is compromised.

When the pandemic started, regulations came in to restrict work. You could not work in person, businesses and companies had to cease their activities, and the movement of people was restricted, only essential services could, under certain rules, function.

The fact is that now that the rules to contain the pandemic have been relaxed and the vaccination against COVID 19 has been implemented, on a non-mandatory basis, a new issue is impacting the relations between employer and employee.

A cleaning assistant at a hospital was fired for just cause after refusing to take the vaccine against the new coronavirus. This conduct was considered by the employer as an act of indiscipline and insubordination.

Article 482, of the Consolidation of Labor Laws defines the possibilities of dismissal for just cause, the maximum penalty applied to the worker.

In the case of the fired employee, she failed to attend the scheduled date for vaccination and received a warning. In the second opportunity she refused to take the vaccine, that is when the employer fired her for just cause.

The judge in his decision said the following: "In view of such circumstances, and considering that the complainant had already been previously warned for the same reason, and at no time tried to justify (either to the defendant, or in court), the reason that would have given rise to the refusal to take the vaccine made available in an emergency and priority manner to the work group to which she belonged (given the risk conditions for working in a risky hospital environment), I am fully convinced that the conduct adopted by the defendant (application of just cause) was not abusive or unreasonable, but absolutely legitimate and regular, because, for all intents and purposes, the complainant did not comply with the company's determination.

\section{Individual Rights x Collective Rights}

The Court understood that it would be unreasonable for the personal interest of the worker to prevail over the collective interest, due to the numerous cases, deaths and sufficient information about the risk of the disease.

Although there is no legal obligation to take the vaccine, companies have assessed the risk to the corporation and, if an 
unvaccinated employee may be responsible for an increase in transmission, besides bringing a feeling of insecurity to other employees who have returned to their work routine.

Much is done to cure some Evil, without compromising the limits of bioethics. Remembering that bioethics connects science, life, and morality. And these principles also guide the law, because while ethics refers to the study of moral values that govern human behavior in society, morality is related to customs, rules, and conventions that each group establishes.

In this context the 4 (four) principles of bioethics: beneficence, non-maleficence, autonomy and justice, teach why the vaccines, even though in a short period of time, were approved. Because the principle of beneficence leads in the direction of maximizing the benefit and minimizing the risk and/or harm to the patient.

In the Hippocratic Oath we find "I will apply the regimens for the good of the patient according to my power and understanding, never to cause harm or harm to anyone", and further, "In every house I will enter there for the good of the sick, keeping away from all voluntary harm...". The principle of non-maleficence minimizes risk and/or harm to the patient, i.e. the Hippocratic axiom "Primum no nocere" (first do no harm).

\section{Conclusion}

The pandemic, caused by COVID-19, has taken the world by surprise. From one moment to another, a public calamity was installed. As a result, habits were changed; autonomy had to be restricted, causing inconvenience to everyone. In the eagerness to find a vaccine, the importance of the human being cannot be relativized. He cannot, even if affected by the disease, subject himself to a new initiative, if it is not of his own will.

However, another aspect cannot be left aside and must not go against the principles of beneficence and nonmaleficence doing well for all and not harming others: The right to life. This is the greatest right that will always be protected. This is the right that will always set aside the individual in favor of the collective good.

The Principle of Autonomy teaches us that, except in a life-threatening situation, it is up to the patient to decide which diagnostic and therapeutic practices he wants to undergo. Autonomy is the ability of an individual to manage his life, using his own means, will, and principles.

Therefore, no one will be forced to vaccinate himself against COVID 19, if he has doubts about the efficacy or any published adverse, side effects. You don't need to apply for experimentation if you are in full capacity to understand what can happen to you, if you choose not to follow what the scientific authorities recommend as safe.

\section{References}

1. Coan EI (2002) Biomedicine and Biolaw. Bioethical Challenges. Semiotic Traits for a Constitutional Hermeneutics Based on the Principles of Human Dignity and the Inviolability of the Right to Life. In: Segre M, et al. (Eds.), Bioetica. $3^{\text {rd }}$ (Edn.), São Paulo: Universidad de São Paulo, Brazil.

2. Pereira HMK (2015) Bio Law as a Place to Develop Legal Perspectives for the Protection of Life. Revista de Direito Sanitário 16(3): 75-81.

3. Farinon MJ (2018) Ethics, justice and education from the perspective of alterity. Cadernos de Pesquisa 48(167): 204-224.

4. Brito ES, Ventura CAA (2013) Bioethics and Biolaw: Reflections in the Light of the Fundamental Principle of Human Dignity. Brazilian Journal of Forensic Sciences, Medical Law and Bioethics 2(2): 141-153.

5. Rivabem FS (2017) Biolaw: an autonomous discipline?. Revista Bioética 25(2): 282-289.

6. Patricia PB (2001) Bioethics, Biolaw and the new responsibilities of legal practitioners in Brazil. Journal of the Faculty of Law, São Bernardo do Campo 7: 240. 